\title{
EFEITO DE EXTRATOS VEGETAIS AQUOSOS SOBRE A GERMINAÇÃO DE PLANTAS DANINHAS
}

\author{
Roberto Andreani Junior ${ }^{1}$; Mayara Queiroz Otero ${ }^{2}$; Matheus Mello Silva ${ }^{3}$ \\ ${ }^{1}$ Professor Doutor da Universidade Brasil (robertoandreani@uol.com.br) \\ Fernandópolis-São Paulo- Brasil \\ ${ }^{2}$ Engenheira Agrônoma da Universidade Brasil .Fernandópolis-São Paulo- Brasil \\ ${ }^{3}$ Discente do curso de Engenharia Agronômica da Universidade Brasil- \\ Fernandópolis-São Paulo- Brasil \\ Recebido em: 06/04/2018 - Aprovado em: 10/06/2018 - Publicado em: 20/06/2018 \\ DOI: 10.18677/EnciBio_2018A41
}

\begin{abstract}
RESUMO
A infestação de plantas daninhas tornou-se um dos grandes problemas da agricultura causando grandes danos as produções e o uso de substâncias alelopáticas na busca por uma agricultura sustentavel é um método de controle alternativo na germinação destas plantas. Desta maneira, este trabalho teve por objetivo testar o possível efeito alelopático de extratos vegetais sobre duas plantas daninhas. $\mathrm{O}$ experimento foi conduzido em laboratório, com delineamento estatístico inteiramente casualisado em esquema fatorial $5 \times 2$, utilizando extratos vegetais de Eucaliptus camaldulensis (eucalipto); Azadirachta indica (neem); Leucaena leucocephalla (leucena) e Annona muricata (graviola) sobre a germinação de Digitaria insularis (capim amargoso) e Bidens pilosa (picão preto), com 4 repetições, totalizando 40 parcelas por teste. Cada repetição foi constituída por 25 sementes dispostas em caixas plásticas "gerbox" contendo papel do tipo "germitest", umedecido a cada dois dias com o respectivo extrato, mantidos em estante de germinação com luz infravermelha acesa por 10 horas, por 21 dias. Observou-se que a germinação das plantas daninhas foi influenciada pelos extratos de modo a inibir ou atrasar a germinação das mesmas. A germinação do capim amargoso foi suprimida pelo extrato de eucalipto, e as sementes de picão preto, foram afetadas pelo extrato de leucena. Não houve expressão do extrato de graviola sobre as sementes das plantas daninhas testadas. Com base nos dados pode-se considerar como efetivo os extratos testados, exceção ao de graviola e que o uso de aleloquímicos é uma ferramenta sustentável e importante na redução das plantas daninhas.
\end{abstract}

PALAVRAS-CHAVE: alelopatia; aleloquimicos; controle.

\section{EFFECT OF PLANT EXTRACTS AQUEOUS ON THE WEED GERMINATION}

\begin{abstract}
A weed infestation has become one of the major problems of agriculture causing great damages to the fields and the use of allelopathic substances in the search for a sustained agriculture is used as an alternative control method in the germination of weeds. The objective of this research was to test the sufficient allelopathic effect of vegetable extracts. The experiment was conducted in a completely randomized
\end{abstract}


design in a $5 \times 2$ factorial scheme, using Eucalyptus camaldulensis (eucalipto) plant extracts; Azadirachta indica (neem); Leucaena leucocephalla (leucena) and Annona muricata (graviola) on a germination of Digitaria insularis (bitter grass) and Bidens pilosa (black pickle), with 4 replicates, totaling 40 plots per test. Each replicate consisted of 25 seeds arranged in a gerbox plastic box containing "germitest" type paper, moistened every two days with the respective extract, kept in germination shelf with infrared light for 10 hours for 21 days. It was observed that weed germination to be influenced by extracts in order to inhibit or delay the germination of their roots. A germination of bitter grass to be suppressed by the eucalyptus extract, and as black pickled seeds, was affected by the leucena extracts. There was no indication of graviola extract on the weed seeds tested. Based on the data can be considered as effective with extracts tested except graviola. It can be stated that the use of allelochemicals is a sustainable and important tool in the reduction of weeds.

KEYWORDS: allelopathy; allelochemicals; control.

\section{INTRODUÇÃO}

O método mais eficaz e poderoso no controle de ervas daninhas é por substâncias químicas denominadas herbicidas. Nos últimos anos, foram publicados muitos dados sobre os diferentes efeitos colaterais destes defensivos agrícolas em humanos, animais, culturas e no meio ambiente como um todo. Assim, o aumento do interesse pelo controle biológico de ervas daninhas tem sido razoável, uma vez que seu melhoramento e expansão contribuirão para limitar o uso excessivo de herbicidas, respectivamente seus efeitos prejudiciais e apoiarão a implementação bem-sucedida do complexo controle de plantas daninhas (SLAVEYA et al., 2015).

Segundo Khawar et al. ( 2015), as ervas daninhas são um inimigo oculto das plantas cultivadas, interferindo em suas funções e suprimindo seu crescimento e desenvolvimento. Perdas de rendimento superiores a $30 \%$ são causadas por ervas daninhas entre as principais culturas. Segundo Lorenzi (2014), um dos grandes problemas que ocorrem em sistemas agrícolas e que causam perdas na produção, é a presença das plantas daninhas que causam interferências diretas e indiretas sobre as plantas cultivadas.

A diversidade de ferramentas de manejo de plantas daninhas garante o seu controle sustentável e reduzem as chances de desenvolvimento de resistência a herbicidas. A alelopatia como ferramenta pode ser usada de forma importante para combater os desafios da poluição ambiental e do desenvolvimento de resistência a herbicidas (KHAWAR et al., 2015).

A alelopatia - interações entre plantas por recursos, juntamente com a concorrência - é um fenômeno composto que possui amplos potenciais de aplicação na agricultura. A compreensão das interações entre plantas, particularmente cultivos, pode ser útil na modificação do padrão de cultivo com consequentes incrementos de produtividade (MAJEED et al., 2017).

A alelopatia influencia o desenvolvimento e crescimento e está definida como o processo que envolve metabólitos secundários produzidos por plantas, fungos algas e bactérias (ALVES, 2013). Parte da planta como um todo ou seu extrato ou seu metabólito pode ser usado tendo efeito alelopático (KUMBHAR;PATEL, 2016).

Contaminação ambiental, desenvolvimento de resistência a herbicidas entre ervas daninhas e problemas de saúde devido ao uso excessivo e indevido de herbicidas sintéticos levou os pesquisadores a se concentrarem em estratégias alternativas de manejo de ervas daninhas. Aleloquímicos extraídos de várias 
espécies de plantas podem atuar como inibidores naturais das ervas daninhas (CHILWAL et al., 2017).

A diminuição da energia de germinação e o tempo prolongado para atingir $50 \%$ de germinação pode ser atribuído à inibição de enzimas respiratórias e enzimas envolvidas na via das pentoses fosfato na germinação de sementes pelos fenólicos presentes em extratos aquosos dessas plantas daninhas (ZOHAIB et al., 2016). Com a alelopatia, as indústrias buscam novos princípios ativos alternativos, procurando fontes mais econômicas, menos tóxicas e mais seletivas no favorecimento da produção agrícola no controle das plantas daninhas e pragas nos cultivos (BORGES et al.,2007; BRASS,2009).

O picão-preto ou piolho-de-padre (Bidens pilosa L.), onde "Bidens" significa dois dentes, referente as projeções do aquênio, e "pilosa", devido aos pelos nas brácteas, é descrita por Lorenzi (2014), como uma planta anual, herbácea, ereta, aromática e pouco ramificada, possuindo de 40 a $120 \mathrm{~cm}$ de altura, sendo considerada uma planta daninha de culturas anuais e perenes (KISSMANN;GROTH, 1992).

A espécie Bidens pilosa apresenta compostos naturais com efeitos alelopáticos sobre plantas. Uma das substâncias é a fenil-heptatrina (PHT) que é um poliacetileno com propriedades medicinais, possuindo radicais livres tóxicos se constituindo em amplo espectro contra organismos concorrentes (SANTOS; CURY, 2011).

É uma planta popularmente utilizada no tratamento de icterícia, malária, reumatismo, asma, conjuntivite, hipertensão, febre, infecções bacterianas e por fungos, contra úlceras, alergias e como cicatrizante. A presença de poliacetilenos e flavonoides nas plantas de picão preto estariam associados a este efeito (GILBERT et al., 2013).

O capim-amargoso (Digitaria insularis L.) é uma gramínea herbácea perene entoucerada, ereta rizomatosa, de colmos estriados com 50 a $100 \mathrm{~cm}$ de altura, com metabolismo fotossintético do tipo C4 (KISSMANN; GROTH,1992). Devido a presença de rizomas, é uma espécie de difícil controle (GEMELLI et al.,2012). É considerada como uma das plantas daninhas mais agressivas que infestam a cultura da cana-de-açúcar (DIAS et al., 2007).

O objetivo desse trabalho foi o de avaliar in "vitro", os possíveis efeitos alelopáticos de extratos vegetais de algumas plantas como: Eucalipto (Eucaliptus camaldulensis); Neem (Azadirachta indica); Leucena (Leucaena leucocephalla) e Graviola (Annona muricata) sobre a germinação de plantas daninhas, sendo elas o Capim amargoso (Digitaria insularis L.) e o Picão-preto (Bidens pilosa L.).

\section{MATERIAL E MÈTODOS}

O experimento foi conduzido em laboratório da Universidade Brasil, localizada na cidade de Fernandópolis ao noroeste do Estado de São Paulo, situada a 20 $0^{\circ} 16^{\prime}$ S., $50^{\circ} 33^{\prime}$ e $483 \mathrm{~m}$ de altitude. Foram realizados cinco tratamentos, sendo eles: testemunha (uso de somente água); extrato de eucalipto (Eucaliptus camaldulensis); extrato de neem (Azadirachta indica); extrato de leucena (Leucaena leucocephalla) e extrato de graviola (Annona muricata).

As folhas das espécies de eucalipto (Eucaliptus camaldulensis); neem (Azadirachta indica); leucena (Leucaena leucocephalla) e graviola (Annona muricata) foram coletadas de plantas nos meses de março, abril e maio. Em seguida foram pesadas e divididas em lotes de $100 \mathrm{~g}$, e cada espécie foi batida em liquidificador por 
três minutos com $300 \mathrm{~mL}$ de água destilada, e posteriormente peneirada e coada em gaze (ALVES, 2013).

As sementes das plantas daninhas utilizadas foram coletadas entre os meses de fevereiro a abril. Utilizaram-se sementes de Capim amargoso (Digitaria insularis) e Picão-preto (Bidens pilosa), em quatro repetições com 25 sementes por teste. Os ensaios de germinação foram realizados em estante de germinação com luz infravermelha acesa por \pm 10 horas, por 21 dias com contagens a cada dois dias, e as sementes das plantas daninhas foram dispostas em caixas plásticas tipo "gerbox" contendo papel de germinação tipo "germitest" esterilizado em autoclave, como substrato.

A aplicação dos extratos foi realizada a cada dois dias, sendo estes preparados em média a cada duas aplicações, pelo mesmo procedimento acima descrito. Junto com as aplicações foram realizadas as contagens e descarte de plântulas germinadas. Todas as parcelas receberam junto com as aplicações dos seus respectivos extratos a aplicação de antifúngico (cetoconazol), de modo a combater o aparecimento de fungos e a posterior interferência no resultado das germinações.

O delineamento estatístico utilizado foi inteiramente casualisado pelo esquema fatorial $5 \times 2$ (tratamentos $\times$ plantas daninhas), com quatro repetições, totalizando 40 parcelas por testes. Os resultados foram analisados pelo programa ASSISTAT e as médias através da analise de variância pelo teste de Tukey a $5 \%$ de probabilidade.

\section{RESULTADOS E DISCUSSÃO}

A Tabela 1 apresenta os resultados obtidos estatisticamente da avaliação do efeito alelopático de extratos vegetais sobre a porcentagem de germinação de duas plantas daninhas.

TABELA 1: Avaliação do efeito alelopático de extratos vegetais sobre a porcentagem de germinação de Bidens pilosa (picão preto) e Digitaria insularis (capim amargoso).

\begin{tabular}{ccc} 
& \multicolumn{2}{c}{ Porcentagem de germinação (\%) } \\
\cline { 2 - 3 } Extrato & Bidens pilosa & Digitaria insularis \\
\hline Água & $19.75 \mathrm{aB}$ & $23.25 \mathrm{aA}$ \\
Annona muricata & $17.62 \mathrm{abA}$ & $17.50 \mathrm{bA}$ \\
Azadirachta indica & $13.00 \mathrm{cB}$ & $16.25 \mathrm{bA}$ \\
$\quad$ Eucaliptus & $15.50 \mathrm{bcA}$ & $10.75 \mathrm{cB}$ \\
camaldulensis & $6.12 \mathrm{~dB}$ & $19.75 \mathrm{abA}$ \\
\hline
\end{tabular}

$\mathrm{CV}(\%)$

16.46

As médias seguidas pela mesma letra minúscula na coluna e maiúscula na linha, não diferem estatisticamente entre si, pelo Teste de Tukey ao nível de $5 \%$ de probabilidade. Fonte: Os autores.

As figuras 1 e 2 dão um panorama geral das germinações e confirmam os resultados de maior eficiência para leucena sobre a germinação do picão-preto (Figura 1), seguida do neem e eucalipto e a baixa influência da graviola. Para o 
capim amargoso (Figura 2), o extrato de eucalipto foi mais efetivo, seguido pelos extratos de neem e graviola. $O$ extrato de leucena foi o menos influente neste ensaio.

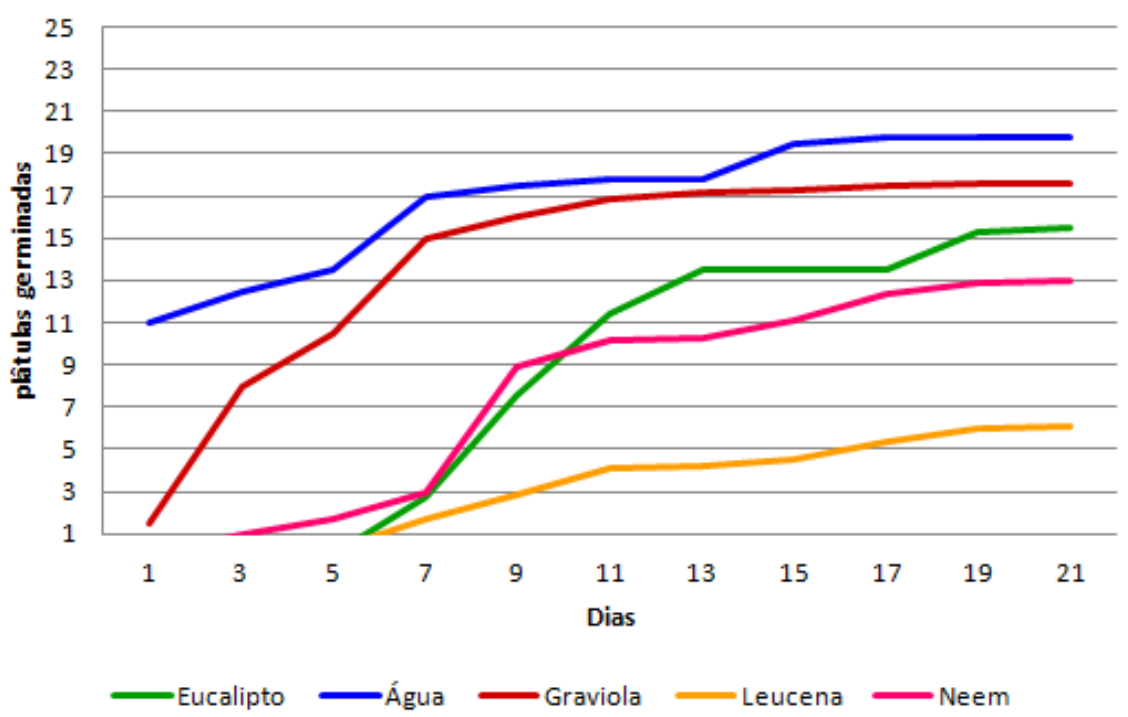

FIGURA 1. Valores médios de todos os extratos sobre a germinação de sementes de Picão Preto.

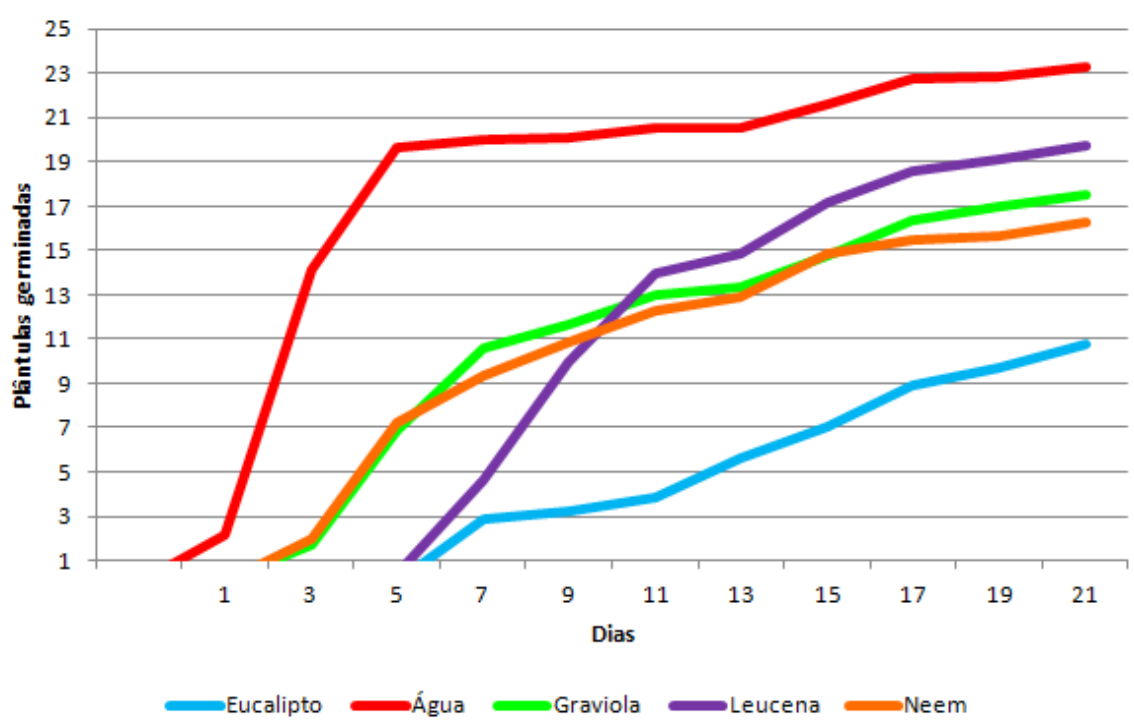

FIGURA 2. Valores médios de todos os extratos sobre a germinação de sementes de Capim Amargoso.

Segundo Inoue et al. (2010), extratos hidroalcoólicos das sementes de Annona crassiflora (araticum), proporcionaram total inibição da germinação e do índice de velocidade de germinação de Urochloa brizantha (capim braquiária) e de Euphorbia heterophylla (amendoim bravo) em relação à testemunha, além de apresentarem representativa inibição da germinação de Ipomoea grandifolia (corda de viola). 
Em estudo sobre o efeito de extratos aquosos de nem (Azadirachta indica), Albuquerque et al. (2015), analisaram o efeito sobre as plantas daninhas picão preto (Bidens pilosa); capim carrapicho (Cenchrus echinatus), jureminha (Desmanthus virgatus) e fedegoso (Senna obtusifolia), em concentrações variáveis, onde pôde-se observar que desde baixas concentrações o extrato analisado, interferiu no processo germinativo. Para todas as sementes houve total inibição na concentração de $100 \%$.

Ferreira et al. (2007), estudaram a interferência alelopatica de extratos etanólicos de eucalipto (Eucalyptus citriodora Hook.) e pinus (Pinus elliottii L.) na germinação e no crescimento inicial do picão-preto (Bidens pilosa L). O extrato de Eucalyptus citriodora reduziu significativamente o índice de velocidade de germinação (IVG) do picão-preto em todas as concentrações testadas quando comparadas com o controle.

Mauli et al. (2009) avaliaram a alelopatia de leucena (Leucaena leucocephala) através de extratos aquosos frios e quentes, em soja (Glycine max) e nas plantas invasoras: corda de viola(Ipomoea acuminata), guanxuma (Sida rhombifolia) e picãopreto(Bidens pilosa). Pôde-se verificar que a utilização de leucena no controle da corda de viola interferiria no seu desenvolvimento e não na sua germinação. $O$ extrato frio de leucena inibiu a porcentagem de germinação de guanxuma a partir da concentração de $60 \%$ e o extrato quente a partir de $80 \%$. O picão-preto teve sua porcentagem de germinação significativamente reduzida pelos extratos quente e frio de leucena a partir de $40 \%$ de concentração, assim como o comprimento de raiz, a partir de 20 e $40 \%$ como nos extratos frio e quente, a velocidade média foi afetada negativamente apenas a partir de $60 \%$ do extrato quente.

Um experimento de laboratório foi conduzido para estudar os efeitos alelopáticos do extrato aquoso de folhas e sementes de leucena (Leucena leucocephala). Os extratos aquosos foram testados individualmente em três espécies de plantas daninhas selecionadas: mentrasto (Ageratum conyzoides); erva de touro (Tridax procumbens) e falsa-serralha (Emilia sonchifolia). A inibição máxima pelo extrato aquoso de sementes foi observada mais na raiz do que no crescimento da parte aérea. $\mathrm{O}$ extrato aquoso de sementes apresentou maiores efeitos inibitorios do que o extrato aquoso de folhas (ISHAK; SAHID, 2014).

A germinação e a partição de biomassa em plantas de arroz (Oryza sativa) foram inibidas por extratos e resíduos de diferentes plantas daninhas (ZOHAIB et al., 2017). A inibição alelopática da germinação e da partição da biomassa no arroz pode ser atribuída aos compostos fenólicos presentes nos tecidos dessas plantas daninhas (ZOHAIB et al., 2014).

Também Neha et al. (2017), observaram que os extratos da raiz e da parte aérea de Echinochloa colona (capim arroz) e Cyperus iria (tiriricão), reduziram a germinação e suprimiram o crescimento inicial de plântulas de arroz (Oryza sativa) e soja (Glycine max). Por outro lado, Awan et al. (2015) sugeriram que o crescimento de Cyperus iria pode ser suprimido pela alta densidade de arroz (400 plantas $\left./ \mathrm{m}^{2}\right)$, mesmo com altas doses de N. A soja (Glycine max) e o milho (Zea mays) foram observados como sensíveis a diferentes espécies de plantas daninhas (BALIČEVIĆ et al., 2014). Babu et al. (2014), observaram que todos os lixiviados de losna branca (Partenium hysterophorus) na concentração de 5,0\% reduziram significativamente a germinação das sementes, o comprimento radicular e do colmo e a matéria seca da grama-preta (Vigna mungo).

Em ensaio de laboratório com sementes de trigo (Triticum aestivum), o impacto mais negativo na germinação de todas as sementes de ervas daninhas (incluindo o trigo), bem como no desenvolvimento de plantas, foi o do extrato aquoso 
de lavanda. Um efeito inibitório significativo da hortelã (Mentha piperita), mesmo em baixas concentrações, foi registrado na germinação de todas as espécies de plantas daninhas testadas enquanto o trigo foi levemente afetado, o que manifesta esta planta como uma espécie potencial em estratégias para o controle de plantas daninhas (SLAVEYA et al., 2015).

Segundo Niteshi e Ambika (2017), o potencial alelopático de cinco plantas daninhas ocasionou a inibição do crescimento da radícula de plantas de trigo. Ainda na cultura do trigo (Triticum aestivum), efeitos alelopáticos de extrato aquoso de diferentes partes da planta (raiz, caule e folha) de artemisia (Artemisia dubia) na germinação de sementes e crescimento de plântulas de trigo e algumas plantas daninhas associadas, Bidens pilosa (picão preto); Ageratum conyzoides (menstrasto); Galinsoga parviflora (picão branco) e Cyperus rotundus (tiririca) foram investigados, sendo que os extratos de raiz, caule e folhas de artemisia apresentaram redução significativa na germinação e crescimento das plantas daninhas (MALIK et al., 2014).

Para identificar o efeito alelopático das espécies de Brassica napus (nabo) e Brassica juncea (mostarda de folha) juntamente com seus métodos de incorporação no controle de plantas daninhas no campo de trigo, Biswar et al. (2014) encontraram que a menor matéria seca de plantas daninhas foi registrada com incorporação total da biomassa de Brassica ao solo. Experimentos de campo e de laboratório foram conduzidos para investigar os efeitos de supressão de ervas daninhas de plantas de cobertura em cultivo único e misto. Verificou-se que a mostarda branca (Sinapis alba L.), o nabo forrageiro (Raphanus sativus var. Niger J. Kern) e a ervilhaca (Vicia sativa L.) suprimiram as ervas daninhas em $60 \%$ (KUNZ et al., 2016).

Nunes et al. (2014), utilizaram extrato aquoso e metanólico de folhas de ipêrosa (Handroanthus heptaphyllus) em concentrações diferentes, para testar sua efetividade na supressão do crescimento de algumas sementes, entre elas a de capim-amargoso (Digitaria insularis), e observaram que o extrato metanólico a $15 \%$ proporcionou uma germinação de apenas $31,6 \%$, sendo o mais efetivo no controle, embora todos as concentrações de água e de extrato metanólico apresentaram interferência na geminação.

\section{CONCLUSÕES}

O uso da alelopatia devido ao seu excelente potencial de interação pode ser considerado uma alternativa viável no manejo de plantas daninhas, possibilitando a utilização dos compostos alelopáticos na produção de bioativos.

Deste modo pôde-se concluir através deste experimento que:

1. O extrato de Leucaena leucocephalla se mostrou o mais eficiente na redução da germinação das sementes de Bidens pilosa;

2. O extrato de Azadirachta indica, ocasionou um atraso na germinação e uma redução na velocidade de germinação das sementes de Bidens pilosa.

3. O extrato de Eucaliptus camaldulensisse mostrou ser o mais eficiente na redução da germinação das sementes de Digitaria insularis e nas sementes de Bidens pilosa, ocasionando um atraso na germinação.

4. O extrato de Annona muricata não mostrou efetividade de controle, inibição ou redução suficiente na germinação de nenhuma das plantas daninhas testadas. 


\section{REFERÊNCIAS}

ALBUQUERQUE, M. B.; GARCIA NETO, S.; ALMEIDA, D. J.; MALTA, A. O. Efeito do extrato aquoso das folhas de nim indiano (Azadirachta indica) sobre o crescimento inicial de plantas daninhas. Gaia Scientia, v. 9, p. 1-6, 2015. Disponível em:< períodicos.ufpb.br/ojs/index.php/gaia/article/view/19211>.

ALVES, P. L. C. A. Potencial alelopático de extratos aquosos de plantas daninhas. In: Manual de Aulas Práticas de Plantas Daninhas. Editores José Ferreira da Silva \& Dagoberto Martins-Jaboticabal: FUNEP, 2013.

AWAN, T. H. P.; CRUZ, C. S.; CHAUHAN, B. S. Growth analysis and biomass partitioning of Cyperus iria in response to rice planting density and nitrogen rate. Crop Protection, v. $74, \quad$ p. 92-102, 2015. Disponível em:< http://dx.doi.org/10.1016/j.cropro.2015.04.010>.

BABU, H. G. P.; VINITA, H.; AUDISESHAMMA, K.; PARAMAGEETHAM, C. H. Allelopathic effects of some weeds on germination and growth of Vigna mungo (L). International Journal Current Microbiology Applied Science, v. 3, p. 122-128, 2014. Disponível em: <https://www.ijcmas.com/Archives-18.php>.

BALIČEVIĆ, R.; RAVLIĆ, M.; KNEŽEVIĆ, M.; SEREZLIJA, I. Allelopathic effect of field bindweed (Convolvulus arvensis L.) water extracts on germination and initial growth of maize. Journal of Animal and Plant Sciences, v. 24, p. 1844-1848, 2014. Disponível em: <https://bib.irb.hr/prikazi-rad?\&rad=743893>.

BISWAS, M. M.; MORSHED, M. J.; ULLAH, I. J. Allelopathic effect of brassica on weed control and yield of wheat P. K. Bangladesh Agronomy Journal, v. 17, p. 7380, 2014. Disponível em: <http://dx.doi.org/10.3329/baj.v17i1.23679>.

BORGES, F. C.; SANTOS, L. S.; CORREAA, M. J. C.; OLIVEIRA, M. N.; SOUZAFILHO, A. P. S. Potencial alelopático de duas neolignanas isoladas de folhas de Virola surinamenses (Myristicaceae). Planta Daninha, v. 25, p .51-59, 2007. Disponível em: < http://Doi org/10.1590/S0100-83582007000100006>.

BRASS, F. E. B. Análise de atividade alelopática de extrato aquoso de falsa murta sobre a germinação de picão-preto e caruru. Enciclopédia Biosfera, v. 5, p. 1-19, 2009. Disponível em: <www.conhecer.org.br/ enciclop/2009B/ANALISE\%20DE \%20ATIVIDADE\%20ALELOPATICA.pdf>.

CHILWAL, A.; SINGH, S. P.; SINGH, V. P.; MAHAPATRA, B. S.; SHUKLA, D. K.; VERMA, $\mathrm{H}$. Determination of allelopathic effect of winter weeds on nutrient content and uptake in wheat. International Journal of Current Microbiology and Applied Sciences, v. $\quad 6, \quad$ p. 978-983, 2017. Disponível em: <https://doi.org/10.20546/ijcmas.2017.612.108>.

DIAS, A. C. R.; CARVALHO, S. J. P.; NICOLAI, M.; CHRISTOFFOLETI, P. J. Problemática da ocorrência de diferentes espécies de capim-colchão (Digitaria spp.) na cultura da cana-de-açúcar. Planta Daninha, v. 25, p. 489-499, 2007. Disponível em: <http://Doi.org/10.1590/S0100-83582007000300008>. 
FERREIRA, M. C.; SOUZA, J. R. P.; FARIA, T. J. Potenciação alelopática de extratos vegetais na germinação e no crescimento inicial de picão-preto e alface. Ciência agrotecnologica, v. 31, p. 1054-1060, 2007. Disponível em: http://dx.Doi.org/10.1590/S1413-70542007000400017.

GEMELLI, A.; OLIVEIRA JR, R.; CONSTANTIN, J.; BRAZ, G.; JUMES, T.; OLIVEIRA NETO, A.; DAN, H.; BIFFE, D. Aspectos da biologia de Digitaria insularis resistente ao glyphosate e implicações para o seu controle. Revista Brasileira de Herbicidas, v. 11, p. 231-240, 2012. Disponível em: < https://Doi.org/10.7824/rbh.v11i2.186>.

GILBERT, B.; ALVES, L. F.; FAVORETO, R. Bidens pilosa L. Asteraceae: (Compositae; subfamília Heliantheae). Revista Fitos, v. 8, p.1-72, 2013. Disponível em: <https://www.arca.fiocruz.br/bitstream/icict/15136/2/16.pdf >.

INOUE, M. H.; SANTANA, D. C.; SOUZA FILHO, A. P. S.; POSSAMAI, A. C. S.; SILVA, L. E.; PEREIRA, M. J. B.; PEREIRA, K. M. Potencial alelopático de Annona crassiflora: efeitos sobre plantas daninhas. Planta Daninha, v. 28, p. 489-498, 2010. Disponível em: <http://www.scielo.br/scielo.php?script=sci_arttext\&pid=S0100$83582010000300005 \&$ Ing=en\&nrm=iso > Doi: 10.1590/S0100-83582010000300005.

ISHAK, M. S.; SAHID, I. Allelopathic effects of the aqueous extract of the leaf and seed of Leucaena leucocephala on three selected weed species. AIP Conference p. 659-664, 2014. Disponível em: <https://Doi.org/10.1063/1.4895280>.

KHAWAR, J.; GULSHAN, M.; VIRENDER, S.; BHAGIRATH, S. C. Allelopathy for weed control in agricultural systems. Crop Protection, v. 72, p. 57-65, 2015. Disponível em: <https://doi.org/10.1016/j.cropro.2015.03.004>.

KISSMANN, K. G.; GROTH, D. Plantas infestantes e nocivas. Editora BASF Brasileira. São Paulo, SP. 1992.789p.

KUMBHAR, B. A.; PATEL, D. D. Allelopathic effects of different weed species on crop. Journal of Pharmaceutical Science and Bioscientific Research, v. 6, p. 801-805. 2016. Disponível em: <J. Pharm. Sci. Bioscientific Res, 2016www.jpsbr.org>.

KUNZ, C. H; STURM, D. J; VARNHOLT, D. F.; WALKER, R. G. Allelopathic effects and weed suppressive ability of cover crops. Plant Soil Enviromental., v.62, p.6066, 2016. Disponível em:<http://www.agriculturejournals.cz/pub> Doi:10.17221/612/2015-PSE.

LORENZI, H. Manual de Identificação de Plantas Daninhas e seu controle. Editora Plantarum, Nova Odessa, SP, 2014. 381p.

MAJEED, A.; MUHAMMAD, Z.; HUSSAIN, M.; AHMAD, H. In vitro allelopathic effect of aqueous extracts of sugarcane on germination parameters of wheat. Acta Agriculturae Slovenica, v. 2, p. 349-356. 2017. Disponível em: < Doi:10.14720/aas.2017.109.2.18>. 
MALLIK, B. B. D.; ACHARYA, B. D.; SAQUIB, M.; CHETTRI, M. K. Allelopathic effect of Artemisia dubia extracts on seed germination and seedling growth of some weeds and winter crops. Ecoprint: An International Journal of Ecology, v. 21, p. 23-30, 2014. Disponível em: <Doi: http://dx.doi.org/10.3126/eco.v21i0.11901>.

MAULI, M. M.; FORTES, A. M. T.; ROSA, D. M.; PICCOLO, G.; MARQUES, D. S.; CORSATO, J. M.; LESZCZYNSKI, R. Alelopatia de leucena sobre soja e plantas invasoras. Semina: Ciências Agrárias, v. 30, p. 55-62,2009. Disponível em: < http://www.redalyc.org/articulo.oa?id=445744091007>.

NEHA, C.; GEETA, T.; LALITM, T.; BRIJU, N. P. Allelopathic effect of Echinochloa colona L. and Cyperus iria L. weed extracts on the seed germination and seedling growth of rice and soyabean. Advances in Agriculture, v. 2017, 5p. 2017. Disponível em: <https://Doi.org/10.1155/2017/5748524>.

NITESH, J.; AMBIKA, J. Study of allelopathic interactions of weeds on of wheat (Triticum aestivum L.) and Moong (Vigna radiata) using Equal-Compartment-Agar Method (ECAM). International Journal of Applied Agricultural Research, v.12, p. 247-254, $2017 . \quad$ Disponível em: <https://www.ripublication.com/ijaar17/ijaarv12n2_14.pdf >.

NUNES,G. L.; ZONETTI, P. C.; ALBRECHT, L. P.; PAULERT, R. Alelopatia de extratos vegetais de Tabebuia sp. sobre a germinação de sementes de plantas infestantes em culturas agrícolas. Journal of Agronomic Sciences, v.3, p.1-9, 2014. Disponível em: <www.dca.uem.br/V3N2/01-Guilherme.pdf>.

SANTOS, J. B.; CURY, J. P. Picão-preto: uma planta daninha especial em solos tropicais. Planta daninha, v.29, p.1159-1172, 2011. Disponível em: <http://Doi.org/10.1590/S0100-83582011000500024>.

SLAVEYA, T. P.; EKATERINA, G.; VALCHEVA, I.; VELCHEVA, G. A case study of allelopathic effect on weeds in wheat. Ecologia Balkanica. v. 7, p. 121-129, 2015. Disponível em: < web. uni-plovdiv.bg/mollov/EB/2015.../121-129_eb.15122.pdf>

ZOHAIB, A.; ANJUM, S. A.; JABBAR, A.; TABASSUM, T.; ABBAS, T.; NAZIR, $U$. Allelopathic effect of leguminous weeds on rate, synchronization and time of germination, and biomass partitioning in rice. Planta daninha, v. 35, e017160380, 2017. Disponível em:< http://dx.doi.org/10.1590/s0100-83582017350100032>.

ZOHAIB, A.; ABBAS, T.; TABASSUM, T. Weeds cause losses in field crops through allelopathy. Not Science Biological, v. 8, p. 47-56, 2016. Disponível em: <Doi: 10.15835/nsb.8.1.9752>.

ZOHAIB, A.; TABASSUM, T.; TASAWER, A.; TASSADDUQ, R. Influence of water soluble phenolics of Vicia sativa $\mathrm{L}$. on germination and seedling growth of pulse crops. Science Agriculturae, v. 8, p. 148-151, 2014. Disponível em: <Doi: 10.15192/PSCP.SA.2014.4.3.148151>. 